\title{
ENTREVISTA CONTINUADA NA CLÍNICA DE LINGUAGEM INFANTIL
}

\author{
Ana Paula Ramos de Souza Ellen Fernanda Klinger ${ }^{\star} \star$ \\ Luciana Borin ${ }^{\star \star \star}$ Rita Maldaner ${ }^{\star \star \star \star}$
}

\begin{abstract}
Resumo
Objetivo: analisar as demandas mais comuns nas entrevistas continuadas entre Fonoaudióloga e os pais de duas meninas com retardo de aquisição da linguagem. Método: foram gravadas as entrevistas com os pais e filmadas as interações mãefilhas. Posteriormente, esses dados foram transcritos e analisados. Resultados: as demandas foram de orientação dos aspectos instrumentais, escuta de aspectos estruturais e da dinâmica familiar. Conclusões: verificou-se a importância dessas entrevistas e o quanto questões da dinâmica do casal interferiam no desenvolvimento das filhas. Houve evolução na terapêutica e nas interações a partir das entrevistas e encaminhamento dos pais à terapia de casal.
\end{abstract}

Palavras-chave: fonoaudiologia; linguagem; subjetividade.

\section{Continued INTERVIEW IN THE CLINICAL OF CHILDISH LANGUAGE}

\begin{abstract}
Aim: to analyze the most common demands in the continued interviews between Phonoaudiologist and the parents of two girls with delayed acquisition of language. Method: the interviews were recorded with the parents and the interactions between mother and child were filmed. Later, these data were transcribed and analyzed. Results: the demands were of guidance of instrumental aspects, listening of structural aspects and of the family dynamics. Conclusions: It was verified the importance of these interviews and how much questions about the dynamics of the couple interfered in the development of his children. There

\footnotetext{
^Fonoaudióloga. Doutora em Lingüística pela PUCRS. Professora adjunta do Programa PósGraduação em Distúrbios da Comunicação Humana da Universidade Federal de Santa Maria (UFSM). Cidade Universitária. Camobi - Km 09 -Santa Maria, RS - Brasil. CEP: 97105-900. E-mail: ramos1964@uol.com.br

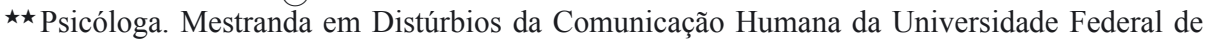
Santa Maria (UFSM).

E-mail: ellenfk@brturbo.com.br

$\star \star \star$ Fonoaudióloga, graduada pela Universidade Luterana do Brasil. E-mail: luborin@hotmail.com

$\star \star \star \star$ Fonoaudióloga. Mestre em Distúrbios da Comunicação pela Universidade Tuiuti do Paraná. E-mail: ritamaldaner@hotmail.com
} 
was progress in therapy and in the interactions from the interviews and guiding of the parents to couple therapy.

\section{Keywords: fonoaudiology; language; subjectivity.}

Durante muitos anos, o trabalho na clínica fonoaudiológica esteve voltado essencialmente para as crianças, sendo que os pais eram chamados somente para participar no momento da entrevista inicial e para alguma eventual orientação. Esta visão se relaciona com as abordagens behavioristas e cognitivistas (PALLADINO, 2004), baseadas na condição intrassujeito, sem considerar a intersubjetividade ou entender a linguagem como um aspecto fundamental na constituição do sujeito.

$\mathrm{Na}$ literatura internacional, o foco ainda se concentra predominantemente na criança, percebendo os distúrbios de linguagem como entidades de base orgânica com consequências linguísticas (CASTRO-REBOLLEDO,2004). Desta forma, há estudos que abordam a arquitetura neuropsicológica destes distúrbios (BUIZA-NAVARRETTTE; ADRIÁN-TORRES; GONZÁLESSÁNCHES, 2007) e outros discutem o papel da inteligência (KEILMAN; BRAUN; SCHÖLER, 2005).

No entanto, alguns trabalhos já começam a considerar o papel da família, ainda que em uma visão mais psicossocial do que psicanalítica (RANNARD; LYONS, 2004). Neste aspecto, o Brasil encontra-se adiantado, já que, em uma perspectiva interacionista atravessada pela psicanálise, há uma visão clínica de linguagem na qual o trabalho familiar é fundamental com crianças que não falam (TERÇARIOL; DELAZERI; SCHILLO, 2003). Esta visão é denominada por Terçariol de clínica da subjetividade, modelo derivado da fonoaudiologia com outras disciplinas e teorias, como o interacionismo proposto por De Lemos (1992), a análise do discurso francesa e a psicanálise.

Considerando os possíveis desdobramentos da referida clínica da subjetividade (TERÇARIOL, 2008) no atendimento de casos de retardo de aquisição da linguagem, os objetivos deste estudo foram: analisar as demandas mais comuns no processo de entrevistas continuadas entre fonoaudióloga e os pais de duas meninas com retardo de aquisição da linguagem, investigando os efeitos dessa estratégia nas interações familiares.

\section{Metodologia}

Os sujeitos participantes da pesquisa foram uma fonoaudióloga responsável pela condução das entrevistas (F), a mãe $(\mathrm{M})$, o pai $(\mathrm{P})$ e as suas duas filhas (S1, S2), ambas com retardo de aquisição da linguagem oral, porém, S1 era portadora de Síndrome de Down e S2 fora acometida por mutismo eletivo. A mãe e as filhas eram atendidas em uma clínica-escola de um município da região metropolitana de Porto Alegre - RS. 
Os procedimentos de coleta incluíram a consulta aos pais, para que os casos de suas filhas juntamente com as entrevistas fossem estudados através de gravações em áudio e filmagens da interação da mãe com cada uma das meninas. Uma vez aceita a pesquisa, foi assinado um termo de consentimento livre e esclarecido, permitindo a divulgação científica dos dados obtidos, respeitando-se a privacidade de sua identidade.

A fonoaudióloga, sujeito da pesquisa, atua na área de linguagem oral e se propôs a executar sistematicamente as orientações que dá usualmente aos pais de pacientes com Retardo na Aquisição da Linguagem (RAL). A mesma tinha contatos esparsos com cursos em desenvolvimento infantil com abordagem psicanalítica e sofrera processo de análise pessoal por dois anos na época. Portanto, não possuía formação acadêmica em psicanálise, embora fosse sensível a questões subjetivas.

Os dados coletados formaram um corpus a partir de três encontros de 45 minutos com os pais, os quais foram gravados em áudio além de ser sido feita filmagem da interação mãe-filhas, em uma sessão de 45 minutos com cada criança. Posteriormente, estes dados foram transcritos literalmente e convertidos para o português escrito e analisados qualitativamente, pela realização de "recortes" das entrevistas, com o intuito de analisar o discurso dos pais e da terapeuta, considerando os seguintes aspectos: tipos de estratégias identificáveis na fala da terapeuta; reações da família com relação à reflexão proposta pela terapeuta; demandas da fonoaudióloga e da mãe quanto a aspectos estruturais e instrumentais do desenvolvimento das meninas.

Já para a análise das filmagens da interação mãe-filhas, foram considerados aspectos como a entonação da voz materna, gestos, compartilhamento de tópico, formas de brincar com a criança.

Os dados coletados neste estudo foram analisados qualitativamente. Para tanto, optou-se pela Análise de Conteúdo, método baseado na dedução e que possui como principal objetivo a inferência (BARDIN, 1979). Inicialmente, transformaram-se os dados brutos através dos procedimentos de recortes em tema (unidade de registro). Assim, nas entrevistas e nas filmagens foi necessário "descobrir os "núcleos de sentido" que compõem a comunicação e cuja presença, ou freqüência de aparição podem significar alguma coisa para o objetivo analítico escolhido" (BARDIN, 1979, p. 105).

Vale ressaltar que, no que se refere aos aspectos estruturais e instrumentais do desenvolvimento das crianças deste estudo, entendem-se como estruturais os que se relacionam com a estruturação do sujeito (afetivo, cognitivo e biológico) e instrumentais aqueles vinculados às características evolutivas objetais da criança, por exemplo, como fala, como se comunica, como aprende, entre outros (CORIAT; JERUSALINSKY, 1993). Assim, ao abordar aspectos estruturais, tanto o terapeuta quanto a família estariam lidando com a visão e o falar familiar acerca do sujeito e, nos instrumentais em habilidades necessárias e como o ambiente familiar pode facilitar seu desenvolvimento. 


\section{ApresentaÇão do Caso}

S1 é uma menina de 2 anos, portadora de Síndrome de Down, residindo na grande Porto Alegre com a mãe (M) e mais dois irmãos de 11 e 3 anos.

A terapia fonoaudiológica com S1 situava-se em um estágio de estimulação precoce, já que iniciara a mesma no primeiro ano de vida e se encontrava em período de estruturação de personalidade. A concepção teórica que embasou a prática foi a interacionista, na qual o sujeito discursivo é o foco principal e não apenas a comunicação e expressão oral.

Um ano antes das intervenções relatadas neste artigo, a irmã de 3 anos de $\mathrm{S} 1$, a S2, também estivera em atendimento fonoaudiológico devido ao mutismo eletivo que ocorreu quando o pai saiu de casa. Esse atendimento foi realizado por outra fonoaudióloga e teve foco cognitivo-linguístico, ou seja, em referencial que não considera os aspectos subjetivos como parte da intervenção fonoaudiológica. Entre os resultados obtidos nas sessões individuais com S2, observou-se que ela voltou a brincar e a falar.

Retornando à clínica-escola para avaliação da linguagem, S2 demonstrou possuir uma estruturação da linguística compatível com sua faixa etária, confirmando que se tratara apenas de mutismo eletivo, embora ainda demonstrasse certa relutância em falar, tristeza e apatia. Em um primeiro momento, a fonoaudióloga sugeriu para a mãe que S2 tivesse atendimento psicológico, mas a mesma demonstrou grande resistência quanto a tal atendimento. Desta forma, através da intervenção familiar, em que os pais participaram de entrevistas continuadas, buscou-se favorecer o desenvolvimento de S2 e S1. Vale lembrar que somente S1 permaneceu em terapia individual.

Ao longo das entrevistas realizadas, verificou-se que havia um problema no exercício da função paterna e, por isso, o pai foi solicitado a comparecer e participar das sessões de S1 quinzenalmente, sendo efetuadas entrevistas sistemáticas com o casal. Antes deste momento, o pai e a mãe voltaram a viver juntos, o que se deu a partir de uma conversa com a fonoaudióloga, que os orientou a procurar uma psicoterapia para o casal, o que acabou por acontecer na sequência do caso.

Analisando o diálogo entre M e S1 na filmagem inicial, observou-se que somente a mãe falava, perguntando, respondendo e fazendo comentários. Já com relação aos gestos e à entonação da mãe, estes eram adequados ao conteúdo da sua fala, contudo, demonstrava não saber brincar com a filha.

Conforme Winnicott (1975), a brincadeira é universal e própria da saúde, sendo que o brincar facilita o crescimento e conduz aos relacionamentos grupais, podendo ser uma forma de comunicação no processo terapêutico, contudo, "as crianças brincam com mais facilidade quando a outra pessoa pode e está livre para ser brincalhona" (WINNICOTT, 1975, p. 67).

Pensando na importância do brincar para o desenvolvimento infantil, Poletto (2005) sugere a criação de programas que promovam a interação entre familiares e as crianças, em que a utilização do lúdico possa ser um instrumento de interação. 
$\mathrm{Na}$ interação da mãe com ambas as filhas, percebeu-se que esta dava turnos, mas que era muito diretiva e restrita na brincadeira, demonstrando pouco entusiasmo para o diálogo.

Ao investigarem as formas de brincar e o ambiente lúdico na interação de 12 díades mãe-criança, MacDonald e Pien (1982) verificaram a prevalência de frases imperativas e questionamentos, bem como a escassez de declarações, que não parecem adequadas na comunicação entre mãe e criança.

Observaram também muitas repetições, principalmente em relação a S1 que tinha poucas possibilidades de fala, o que estava relacionado à dificuldade sentida pela mãe em lidar com a deficiência da filha.

Já na análise da interação entre M e S2, observou-se maior adequação, pois a mãe apresentou boa sintonia, fazendo perguntas e oferecendo oportunidades para a menina responder, bem como respondendo às perguntas da filha, com gestos e entonação adequados ao conteúdo da sua fala. No entanto, semelhantemente ao que foi observado em relação a $\mathrm{S} 1$, demonstrava falta de entusiasmo e experiência em brincar com a criança. Essa falta de entusiasmo parece ficar mais clara quando se analisam as demandas no processo de entrevista continuada.

\section{Questões de RELACIONAMENTO FAMILIAR QUE VÃo ALÉM DA DEFICIÊNCIA DE S1 E ACABAM ABORDANDO S2}

Em entrevista com os pais, foram ressaltadas algumas dificuldades na esfera afetiva observadas em S2, já que a criança estava em reavaliação e com possível alta fonoaudiológica. $\mathrm{O}$ tema surgiu quando falavam da inclusão de S1 na escola.

F: "Eu acho que teria muito benefício a S1 entrar num maternal comum porque ela está se desenvolvendo super bem e nós acompanharíamos a inclusão dela. E a S2 ter também. Numa turma, de preferência, separada, mas na mesma escola. (...) A S2 está com um comportamento de sempre querer estar junto com a irmã, não sei se tu notou isto?"

M: "É coladinha, ela briga para dormir com a irmã."

F: "E o que tu achas que é isto?"

M: "Acho que é falta do pai dela. A outra vez que me separei ela parou de falar."

A orientação oferecida pela fonoaudióloga nesta situação foi instrumental, abordando a importância da inclusão escolar para S1 e S2, que deveriam ficar em salas separadas. Também não deixa de abordar aspectos estruturais quando aponta o comportamento das duas de sempre estarem muito juntas. Porém, a mãe relaciona à intimidade das duas relacionadas à falta do pai, o que demonstra o quanto ela escapa da reflexão sobre sua relação com as filhas, como por exemplo, o fato de seu foco durante as vindas das crianças à clínica ser maior em S1 do que em S2. Isso explicaria a necessidade de S2, na ausência do pai, que lhe 
dava mais atenção, precisar estar colada à irmã para tentar ser percebida pela mãe. Por outro lado, indica a demanda constante em falar desse marido, em geral atribuindo-lhe as dificuldades familiares.

Suspeitando que o atraso de linguagem de S2 seja um sintoma manifestado em função da relação/separação dos pais entre si e com as filhas, a fonoaudióloga abordou a necessidade de presença deste nas entrevistas e terapia, inclusive para discutir questões relacionadas a S2.

Cabe ressaltar que o momento inicial da terapia de S1 e S2 não se deu com a fonoaudióloga desta pesquisa e que o "mutismo" apresentado por S2 quando o pai saiu de casa não foi abordado com a entrada da psicologia, conforme a própria mãe, embora não concorde, anuncia ao dizer que ela parou de falar quando o pai saiu de casa. Por outro lado, até aquele momento, o pai nunca havia sido chamado à clínica.

Em seguida, a mãe relata como percebe a relação do pai com $\mathrm{S} 1$, falando que ele tem dificuldade dele em aceitar a deficiência da filha, que "as meninas são problemas para eles" (o pai e sua família de origem). Entretanto, há momentos em que relata o interesse dele em ajudar na organização do quarto das crianças, mas que não consegue aceitar a opinião do mesmo.

A partir disso, outra hipótese levantada pela fonoaudióloga é que ,além dessa dificuldade, pode haver uma desqualificação desse pai por parte da mãe.

M: "Ele ficou preocupado achando que a S1 ia cair, queria colocar um negócio, fazer uma gradezinha na cama".

F: "Que bom, envolve ele, diz: "Eu acho que tu tens razão, ela pode cair", dá razão pra ele em algumas coisas. Ele está tão inseguro, ele não pode substituir a família dele por ti, ele tem que se autoafirmar para se independizar daquela família lá atrás, ele tem que entender que ele também decide da família dele."

Nos trechos destacados acima, a fonoaudióloga tentou dialogar sobre o relacionamento familiar, sugerindo para a mãe que dê autoridade a este pai, mostrando que ele representa a lei. Conforme Faria (2005), o que vem dar lugar à função paterna é o desejo materno, sendo o pai, a figura paterna, quem permite a passagem e o acesso da criança ao mundo simbólico.

Observou-se também o olhar atento da fonoaudióloga para o discurso dos pais, o que a possibilita (re) construir o papel das crianças, e de seus pais, na narrativa familiar (TFOUNI; FERRIOLI, 2000).

\section{ACEITAÇ̃̃o da deficiênCIA da FILHA PElos Pais}

M: "Ela fala mamã, nenê, (nome do irmão) só que ela bota um metro de língua pra fora pra dizer, mas ela tenta. Nenê ela aprendeu a falar e bola também essa semana".

Percebe-se que, quando a mãe fala que a filha põe um "metro de língua pra fora para falar", é um jogo dialético que faz para aceitar a deficiência. Enquanto ela precisa verbalizar isto, nota-se que a aceitação da deficiência não é algo que 
está totalmente pronto. Os mais diversificados sentimentos são vivenciados pelos pais de uma criança deficiente como, por exemplo, o choque, a raiva e a culpa, até que estes cheguem à aceitação, o que ocorre quando superam o seu pesar e passam a aceitar-se novamente como pais (LUTERMAN, 1984; IERVOLINO; CASTIGLIONE; ALMEIDA, 2003).

Prado (2006) e Battikha (2008) assinalam que, quando os bebês nascem com algum tipo de malformação ou com algum distúrbio importante do desenvolvimento, tornam-se mais complicadas a adaptação e a aceitação desse filho em relação ao que foi idealizado. Nesses casos, os pais têm de lidar com grandes frustrações de seus projetos e sonhos, o que se constitui em um grande desafio.

M: "Ela nasceu na segunda-feira e o médico me falou (referindo-se a S1) na quinta, quando eu fui dar mamá no hospital. O meu marido foi comigo, daí o médico falou pra mim e eu disse pra falar também pra ele, porque se eu fosse falar a gente ia brigar. A reação dele foi assim, "Ah, está bom, se é minha filha fazer o quê?"

Neste fragmento, a mãe expõe a dificuldade do pai em aceitar a deficiência da filha e também a sua, estando num momento de maior aceitação, mas ainda, de assimilação da deficiência, acabando por relatar indireta e veladamente seu choque. Vê-se o quanto projeta alguns de seus sentimentos sobre o marido, embora possa se perceber que este realmente possuía uma dificuldade para assimilar a deficiência da filha, quando se analisam trechos de sua fala como: "não sei o que eu fiz de errado para ter um filho assim. Nunca debochei de nenhuma criança deficiente".

Nessa fala, o pai demonstrou um pensamento mágico sobre a deficiência poder ser um tipo de castigo a algo errado que tenha feito. A fonoaudióloga deulhe explicações sobre isso poder acontecer a qualquer um, sem que tenha feito algo errado, propôs que o pai viesse uma vez por semana e entrasse nas sessões com S1. Esse fato desencadeou um maior cuidado e compreensão do mesmo em relação à filha, bem como mais contato físico e afetivo entre os dois.

Nas primeiras sessões, a menina rejeitava as ações do pai, mas, com a sequência do trabalho, passou a reconhecer sua presença e a solicitar sua ajuda em momentos de necessidade. A presença da figura paterna parece ter auxiliado S1 a evoluir no acesso ao simbólico (BERNARDINO, 2008), tanto em relação ao brincar (faz-de-conta cada vez mais frequente) quanto na produção de suas primeiras palavras.

No entendimento de Prado (2006), uma criança que chega ao mundo com alguma malformação traz um sofrimento enorme para os pais, fere profundamente sua auto-estima, mina seu senso de competência, afeta seu "narcisismo", numa linguagem psicodinâmica, sendo que, quanto mais visíveis essas forem, mais imediatamente determinarão nos pais preocupações e constrangimentos. A colocação do autor vai ao encontro do que pode ser observado no comportamento do pai em relação a S1, sendo necessária a intervenção da Fonoaudióloga, no sentido de mostrar que, mesmo com as limitações impostas pela síndrome, a filha era uma menina esperta, cheia de possibilidades. Este artifício foi utilizado para ressignificar a deficiência da menina, a fim de que o pai pudesse vê-la de outra forma e aceitá-la. 
F: “Apesar de ela ser assim, é uma criança que tem um bom potencial. Ela pode desenvolver, não vai ficar normal. Mas dentro do ritmo dela, é uma criança muito inteligente e querida."

Na sequência terapêutica, observou-se que o casal continuava com momentos de desentendimento. Numa das tardes em que compareceram à clínica, ambos demonstravam estarem em crise e a mãe chorava na sala de espera. A fonoaudióloga, percebendo a crise do casal, conseguiu falar com a mãe e depois com pai, e, em seguida, com ambos, durante o atendimento das meninas e encaminhá-los para terapia de casal. Felizmente, o setor de psicologia da clínica conseguiu ser contatado imediatamente e a psicóloga iniciou o atendimento do casal no outro dia.

A sequência do processo terapêutico das meninas transcorreu muito melhor a partir da resolução dos problemas do casal, cujo casamento de fato parece ter melhorado a partir daquele processo. A percepção da dinâmica familiar que interferia no desenvolvimento geral e de linguagem de S1 e S2 facilitou a evolução de ambas. Esse fato demonstra que, na clínica da subjetividade, a linguagem é pensada como funcionamento simbólico, e não como instrumento de representação de conteúdos cognitivos, psíquicos e biológicos (TERÇARIOL, 2008). Nesta perspectiva, é necessário que o fonoaudiólogo esteja atento aos fatores subjetivos, sabendo identificá-los e, também possa orientar ou sugerir de uma forma adequada que a família busque auxílio. Para tanto, precisa trabalhar em uma perspectiva interdisciplinar.

Pavone e Rubino (2003) - psicanalista e fonoaudióloga - salientam que a aproximação entre clínicas não é algo simples, ao passo que intervenções distintas são encontradas e quem se ocupa desta prática tem conhecimento de que ainda está por ser escrita. Mas a experiência interdisciplinar produz a soma de saberes distintos e a particularidade do objeto que pode ser recortada e que se desdobrará na escolha de uma especialidade.

Conforme Filidoro (1999), a noção de interdisciplinaridade propõe uma posição ante a clínica, que obriga o profissional a reformular a sua técnica, à luz do que o paciente produz, no entanto, sem se afastar dos limites de sua disciplina. $\mathrm{O}$ conhecimento deve ser construído em conjunto com a equipe, não alargando e nem fragmentando o paciente em diferentes saberes.

A interação entre a clínica de fonoaudiologia e de psicologia parece ter sido fundamental para o encaminhamento positivo de suas resoluções, tanto em termos de evolução de linguagem das meninas quanto na diminuição do sofrimento familiar.

\section{CONSIDERAÇÕES FINAIS}

Neste artigo, através de entrevistas com os pais, investigaram-se as possibilidades na clínica fonoaudiológica e que reflexões surgem sobre a inclusão destes na terapia, em que a partir da análise e discussão dos dados foi possível obter algumas considerações. 
Em relação a possibilidades da clínica fonoaudiológica, aparecem demandas estruturais e instrumentais, o que se observou na análise das orientações práticas da fonoaudióloga em relação aos pais. Acredita-se que outro ponto pertinente é que mesmo as demandas parentais por aspectos instrumentais apareciam atravessadas por questões estruturais, como as dificuldades na relação do casal e, consequentemente, na dinâmica familiar, e a aceitação da deficiência de S1.

Quanto às reflexões sobre a intervenção feita em relação aos pais, este estudo demonstrou que é recente a preocupação com a inclusão destes na prática clínica em fonoaudiologia, o que se reflete em uma ausência de sistemática e de um plano para incluir os mesmos. Assim, embora a fonoaudióloga, sujeito desta pesquisa, se esforce em fazer o melhor para a orientação, falta-lhe uma teoria de apoio que auxilie a escolher as melhores técnicas de entrevista.

O que este trabalho indica é que há necessidade na formação em fonoaudiologia, sobretudo do profissional que trabalha com a linguagem infantil, da inclusão de conteúdos teóricos e práticos mais direcionados para a área de entrevistas, e do uso deste instrumento como algo sistemático na terapêutica infantil.

Por fim, cabe salientar a importância da realização de um trabalho conjunto com o setor de psicologia, como neste caso, em que a experiência da fonoaudiologia com a psicologia revelou-se valiosa. Ressalte-se, no entanto, que tal valor será ampliado se houver um domínio da teoria psicanalítica pelos profissionais de ambas as áreas, uma vez que nessa perspectiva o sujeito é constituído da/na linguagem.

\section{REFERÊNCIAS}

BARDIN, L. Análise de conteúdo. Lisboa: Edições 70, 1979.

BATTIKHA, E. C. A inscrição do estranho no familiar. In: KUPFER, M. C. M.; TEPERMAN, D. (Org.). O que os bebês provocam nos psicanalistas. São Paulo: Escuta, 2008. p. 135-145.

BERNARDINO, L. F. Aspectos psíquicos do desenvolvimento infantil. In: WANDERLEY, D. B. (Org.). O cravo e a rosa - a psicanálise e a pediatria: um diálogo possível? Salvador: Ágalma, 2008. p. 54-66.

BUIZA-NAVARRETE,J.J; ADRIÁN-TORRES, J. A; GONZÁLEZ-SÁNCHEZ, M. Marcadores neurocognitivos en el trastorno específico del lenguaje. Revista de Neurologia, Barcelona ,v. 44, n. 6, p. 326-333, jan/jun. 2007.

CASTRO-REBOLLEDO, R. et al. Trastorno especifico del desarrollo del lenguaje: una aproximación teórica a su diagnóstico, etiología y manifestaciones clínicas. Revista de Neurología,Barcelona, v. 39, n.12, p. 1173-1181, jul/dec. 2004. 
CORIAT, L. F.; JERUSALINSKY, A. N. Definição de estimulação precoce. Escritos da Criança. Porto Alegre: Centro Lydia Coriat, 1993. n. 1.

DE LEMOS, C. T. G. Los procesos metafóricos y metonímicos como mecanismos de cambio. Substratum, Barcelona, v. 1, n. 1, p. 121-135, 1992.

FARIA, M. R. O que é um pai para uma criança? Considerações sobre o caso Hans. Estilos da Clínica, São Paulo, v. 10, n. 19, p. 154-161, jun/dez. 2005

FILIDORO, N. S. Algumas reflexões em torno da clínica psicopedagógica. Revista da Associação Psicanalítica de Porto Alegre, Porto Alegre, v. 9, n. 16, p. 75-91, 1999.

IERVOLINO, S. M. S.; CASTIGLIONE, M.; ALMEIDA. K. A orientação e o aconselhamento no processo de reabilitação auditiva. In: ALMEIDA, K.; IORIO M. C. M (Org.). Próteses auditivas. São Paulo: Lovise, 2003. p.411-427.

KEILMANN, A.; BRAUN, L.; SCHÖLER, H. Diagnosis and differentiation of children with language development disorders. What role can be attributed to intelligence? HNO, Berlin, v. 53, n. 3, p. 268-284, März 2005.

LUTERMAN, D. Counseling the communicatively disordered and their families. Boston: Little Brown and Company, 1984.

MACDONALD, L.; PIEN, D. Mother conversational behavior as a function of interactional intent. Journal of Child Language, Cambridge, v. 9, n. 2, p. 337-358, Apr./June 1982.

PALLADINO, R. Desenvolvimento da Linguagem. In: FERREIRA, L. P. et al. (Org.). Tratado de fonoaudiologia. São Paulo: Roca, 2004. p. 763-771.

PAVONE, S.; RUBINO, R. Da estereotipia à constituição da escrita num caso de autismo: dois relatos... um percurso. Estilos da clínica, São Paulo, v.8, n. 14, p. 68-89, jan./jun. 2003.

POLETTO, R. C. Ludicidade e contexto familiar. Psicologia em Estudo, Maringá, v. 10, n.1, p. 67-75, jan./jun. 2005.

PRADO, L. C. Entre a realidade e os sonhos: o desafio das famílias com bebês. Porto Alegre: L. C. Prado, 2006.

RANNARD, A.; LYONS, C.; GLENN, S. Children with specific language impairment: parental accounts of the early years. Journal of Child Health Care, London, v. 8, n. 2, p. 165-176, Jun./Sep. 2004. 
TERÇARIOL, D.; DELAZERI, F.; SCHILLO, R. No discurso de estagiários e recém-formados: porque incluir os pais no processo terapêutico fonoaudiológico de seus filhos. Distúrbios da Comunicação, São Paulo, v. 15, n. 2, p. 309-334, jul./dez. 2003.

TERÇARIOL, D. A clínica fonoaudiológica: da prática à construção de fundamentos teórico-metodológicos. In: GRAÑA, C. G. (Org.). Quando a fala falta: fonoaudiologia, linguística e psicanálise. São Paulo: Casa do Psicólogo, 2008. p. 79-94.

TFOUNI, L. V.; FERRIOLLI, B. H. V. M. O discurso dos pais e a gênese do retardo de linguagem na criança. Pró-fono, Barueri, v. 13, n. 1, p. 62-66, set. 2001.

WINNICOTT, D. W. O brincar e a realidade. Rio de Janeiro: Imago, 1975.

Recebido em: março de 2009

Aceito em: setembro de 2009 